\title{
Germination of Ascospores of Gibberella zeae After Exposure to Various Levels of Relative Humidity and Temperature
}

\author{
J. Gilbert, S. M. Woods, and U. Kromer
}

Cereal Research Centre, Agriculture and Agri-Food Canada, 195 Dafoe Road, Winnipeg, MB, R3T 2M9.

Accepted for publication 31 January 2008.

\begin{abstract}
Gilbert, J., Woods, S. M., and Kromer, U. 2008. Germination of ascospores of Gibberella zeae after exposure to various levels of relative humidity and temperature. Phytopathology 98:504-508.

Fusarium head blight (FHB) is one of the most important cereal diseases in the world and has caused major losses to the grain industry. The principal pathogen causing FHB in North America is Gibberella zeae (anamorph Fusarium graminearum). Information on survival and the conditions under which ascospores remain viable once released from perithecia may assist in refining disease forecasting models. This study measured germination of ascospores after exposure to different tempera-

tures, 15,20 , and $30^{\circ} \mathrm{C}$, and levels of relative humidity (RH), 30, 60, and $90 \%$ for 4,24 , or $48 \mathrm{~h}$ periods. Viability was tested by germination on water agar. Germination rates fell with increasing temperatures at all observation times and at all humidity levels. At 15 and $20^{\circ} \mathrm{C}$ after $48 \mathrm{~h}$, germination ranged from 74 to $85 \%$, and 52 to $72 \%$, respectively. At $30{ }^{\circ} \mathrm{C}$, germination ranged from 36 to $59 \%$ after $24 \mathrm{~h}$ and from 13 to $47 \%$ after $48 \mathrm{~h}$. Germination was highest at $90 \% \mathrm{RH}$, except at $30^{\circ} \mathrm{C}$ after $48 \mathrm{~h}$, and lowest at $60 \% \mathrm{RH}$. Successful germination, even under extreme conditions, suggests that ascospores are sufficiently robust to constitute a source of inoculum under most environmental conditions encountered during the growing season.
\end{abstract}

Gibberella zeae (Schwein.) Petch (anamorph Fusarium graminearum Schwabe), the causal agent of Fusarium head blight (FHB) in North America is responsible for losses to all sectors of the grain industry (7). The fungus produces perithecia and ascospores, the primary source of inoculum, on overwintered crop residues. The conditions under which perithecia develop, and ascospores mature and are released to the environment have been documented well, although some disparity exists in the results reported $(3,4,8,10,19)$. There are also published reports on dispersal and deposition $(4,8-10,15)$, but relatively little is known about the conditions under which spores remain viable over time and germinate $(2,17)$.

Under controlled conditions, perithecial development slowed or was limited at low moisture levels of -2.36 to $-4.02 \mathrm{MPa}(-23.6$ to -40.2 bars) and at extremes of the temperatures tested in one study, a low of $12^{\circ} \mathrm{C}$ and a high of $28^{\circ} \mathrm{C}$ (3). Sung and Cook (17) noted that perithecial production was maximal at -15 bars $(-1.5 \mathrm{MPa})$. As the water potential of the culture medium dropped, isolates of $F$. graminearum produced fewer macroconidia and more perithecia, which under natural conditions would correspond to the development of perithecia on drying plant tissues.

Ascospore release has been reported to display a diurnal periodicity and a correlation with rainfall events. More spores were trapped between 2 and 7 days following rainfall events and numbers of trapped spores increased with rising $\mathrm{RH}$ in the evening starting around $1600 \mathrm{~h}$ and peaking sometime before midnight $(4,8,10)$. It was also reported that low numbers were trapped during the morning hours, under continuous high $\mathrm{RH}$ $(>80 \%)$ or during a day of rainfall exceeding $5 \mathrm{~mm}$ (10). Disparity exists between these results and those of Trail et al. (19), who under controlled conditions using a wind tunnel found that maximum spore discharge occurred when $\mathrm{RH}$ exceeded $92 \%$. In

Corresponding author: J. Gilbert; E-mail address: jgilbert@agr.gc.ca

doi:10.1094/PHYTO-98-5-0504

(c) 2008 Department of Agriculture and Agri-Food, Government of Canada some studies ascospore release appeared to occur during the evening hours, suggesting that more spores were discharged during hours of darkness than in light, but Trail et al. (19) found 8 to $30 \%$ more ascospores were released in light than in darkness. In terms of dispersal, Maldonado-Ramirez et al. (9) trapped spores from the planetary boundary layer at all hours of the day and night, but Schmale et al. (15) reported that more spores were trapped at night with major deposition events coincident with rain. While the majority (93\%) of spore deposition events were random in distribution, the remaining $7 \%$ were aggregated and all occurred at night (15).

Earlier reports indicated a limited dispersal distance of ascospores, measured in just meters from a source of inoculum (5). These results suggested that ascospores would need to land on susceptible host tissue and germinate rapidly after discharge for effective infection. However, Francl et al. (6) demonstrated that spores of $G$. zeae could be found on trap plants located on the roofs of buildings several kilometers from any agricultural crops. More recently, strong evidence for the long-distance dispersal of G. zeae spores was obtained through the use of remote-piloted vehicles which sampled air in the planetary boundary layer between $50 \mathrm{~m}$ and $1 \mathrm{~km}$ above the surface of the earth (9). Viable spores were collected at all hours of the day and night from air sampled at approximately $60 \mathrm{~m}$ above ground level. More ascospores were trapped on cloudy days than on clear days.

In comparison to our understanding of ascospore release and deposition, relatively little is known about the survival of ascospores once they have been discharged from the perithecium. Sung and Cook (17) noted that as water potential decreased so did germination. At water potentials between -1 and -20 bars $(-0.1$ and -2.0 MPa), germination of both macroconidia and ascospores was maximal, but macroconidial germination decreased rapidly to zero after 8 or $12 \mathrm{~h}$ at -60 bars $(-6.0 \mathrm{MPa})$. After $24 \mathrm{~h}$ at -80 bars (-8.0 MPa), approximately $50 \%$ of the ascospores still germinated. Beyer and Verreet (2) examined the germination of ascospores as affected by age of spores since dispersal and environmental factors, and reported that ascospores of $G$. zeae lose their ability to germinate as a result of exposure to low $\mathrm{RH}$ within a 
few minutes. Consequently, they concluded that long-distance dispersal would not be feasible if the spores were subjected to relative humidity $(\mathrm{RH})$ of less than $50 \%$. In their environment, they determined that there were adequate levels of $\mathrm{RH}$ to retain ascospore viability. However, in the eastern Prairies of Canada $\mathrm{RH}$ may be very low during growing season daylight hours. The mean RH values for the months of May, June, and July for 2001, for example, were 47,52 , and $55 \%$ respectively. The minimum $\mathrm{RH}$ for many days was less than $50 \%$ between noon and $1800 \mathrm{~h}$ (Environment Canada). More ascospores are released during daylight hours (19), but may lose viability within a few minutes of exposure to low RH (2). However, FHB is endemic under such conditions of low $\mathrm{RH}$ in the eastern prairies of Canada. The objective of this study was to examine the effect of different temperatures, $\mathrm{RH}$ levels, and exposure times on the germination of G. zeae ascospores.

\section{MATERIALS AND METHODS}

Saturated solutions were created using the salts $\mathrm{MgCl}_{2} \cdot 6 \mathrm{H}_{2} \mathrm{O}$, $\mathrm{NaBr} \cdot 2 \mathrm{H}_{2} \mathrm{O}^{5}$, and $\mathrm{KNO}_{3}{ }^{11}$ to provide $\mathrm{RH}$ levels of approximately 30, 60, and 90\% (Table 1) (20). Saturated salt solutions were placed in the bottom of 11.4 liter clear boxes (Rubbermaid) to create portable chambers at a stable RH level. Slides with ascospores were supported in styrofoam blocks, which were placed on wire mesh grids above the salt solution inside the chamber. Within each chamber a thermohygrometer (Model 1458-59, Taylor Precision Products, Las Cruces, NM) monitored temperature and $\mathrm{RH}$, and small fans kept air circulating. Small quantities of water or salts were added when the hygrothermographs registered a different value from the expected value. The humidity chambers were placed in a culture chamber (Model CMP3244, Conviron, Winnipeg, Manitoba) set at 15,20 , or $30^{\circ} \mathrm{C}$, with cool white fluorescent light bulbs emitting 20 lux. Ascospores were exposed for 4,24 , or $48 \mathrm{~h}$.

Three isolates of G. zeae (207-03-1, 207-03-2, and 207-03-4), obtained from infested wheat seed in Manitoba, Canada in 2003, were first grown on circles of sterile filter paper (Whatman No. 3) placed on potato dextrose agar in $90 \mathrm{~mm}$ petri dishes. After the filter paper was colonized, it was peeled from the agar under aseptic conditions and allowed to dry in a biohazard hood. Subsequently, the colonized paper was cut into $4 \mathrm{~mm}^{2}$ pieces and frozen at $-20^{\circ} \mathrm{C}$ to create a stock supply from which future cultures were grown for all experiments. G. zeae cultures were started from a piece of colonized filter paper using $60 \mathrm{~mm}$ plates of carrot agar (400 g of carrots autoclaved in $400 \mathrm{ml}$ of distilled water and pureed, added to $500 \mathrm{ml}$ of distilled water and $20 \mathrm{~g}$ of agar, and autoclaved again) and grown under fluorescent cool white light (20 lux) in an incubator at $20^{\circ} \mathrm{C}$ for 5 days. The mycelium was then flattened under sterile distilled water with a glass rod, and placed under UV/white light with a 16/8 h photoperiod for 6 to 8 days to induce perithecia and ascospore development. When ascospores were discharged from perithecia and observed on the lid of the petri dish, a new lid was misted with sterile distilled water and placed over the culture to permit the collection of ascospores in suspended condensation droplets on the petri dish lids. In order to locate condensation droplets that actually contained ascospores, the petri dish lids were examined microscopically (Fig. 1). At this point we were able to ascertain that no spores had germinated before exposure to different temperature and RH conditions. Ascospores were collected within $24 \mathrm{~h}$ of being released from perithecia. One droplet $(25 \mu \mathrm{l})$ of the spore suspension was placed on the frosted end of a glass microscope slide and dried rapidly in a biohazard hood. Three slides of each isolate of $G$. zeae, were placed horizontally onto styrofoam supports in each humidity chamber and placed into the culture cabinet at the desired temperature. One slide for each isolate was removed at 4,24 , or $48 \mathrm{~h}$ exposure periods from each of the $\mathrm{RH}$ chambers. After exposure, the spores were washed from the slide onto a water agar plate and incubated overnight in the dark at ambient laboratory temperature $\left(20\right.$ to $\left.23^{\circ} \mathrm{C}\right)$. Two counts of spore germination (at least one germ tube visible) were made using random groups of 100 spores, and the average percent germination recorded. The procedure was carried out once a week for 4 weeks at the same temperature with freshly generated ascospores (four replicates). There were three G. zeae isolates, three $\mathrm{RH}$ levels, and three temperature regimes, and the entire experiment was repeated once.

A separate mixed model was fitted to arcsine square root transformed germination data for each exposure time, using the SAS PROC Mixed procedure (12). Fixed effects were temperature, $\mathrm{RH}$, and their interaction. Random effects were repetition, repetition by temperature, and interactions of repetition by temperature with replicate and RH. Isolate and two- and threeway isolate interactions with temperature and RH were also treated as random. A simpler model, omitting isolates and their interactions, was also fitted and fit statistics compared. Linear temperature trends were tested using contrasts.

\section{RESULTS AND DISCUSSION}

At 4 and $24 \mathrm{~h}$ exposure, the simpler model (isolates and interactions omitted) was the better and adding the extra parameters did not improve the fit (data not shown). At $48 \mathrm{~h}$ exposure, there was little difference between the two models in terms of fit. Consequently, the simpler model was used and the data for the isolates were combined for analysis.

In early studies of fungal spore germination, concerns were raised about the use of saturated salt solutions to achieve $\mathrm{RH}$ greater than $90 \%$ in humidity chambers (13). As temperature drops occur in incubators, condensation occurs and more time is required for the salt solution to reabsorb the moisture than may elapse before the next cycle occurs. Ayerst (1) also commented on the fact that this effect may be more pronounced when spores are exposed on a nonhygroscopic surface such as glass. However, the use of the frosted end of a microscope slide allowed us to spread the spore suspension and dry off the excess water rapidly. Second, the use of fans to circulate the air and hygrothermographs to monitor RH and temperature precluded the possibility of condensation providing free water during exposure of spores to different temperatures and RH levels. No condensation was observed during the experiment and spores were checked between exposure and placement on water agar for any germination that might have occurred during the exposure periods. No germinated spores were seen.

Germination rates fell significantly with increasing temperatures after all exposure times (T Linear, Table 2). Relative humidity was a significant factor at 4 and $24 \mathrm{~h}$, but not at $48 \mathrm{~h}$. The interaction between $\mathrm{RH}$ and temperature was significant only after $4 \mathrm{~h}$ exposure. The linear effect of temperature on germination was significant for all exposure periods except $4 \mathrm{~h}$ at $90 \%$ $\mathrm{RH}$ (Table 2). Germination rates fell with higher temperatures after all exposure times and at all humidity levels. After $48 \mathrm{~h}$ exposure, germination at 15 and $20^{\circ} \mathrm{C}$ ranged from 74 to $85 \%$, and 52 to $72 \%$, respectively. At $30^{\circ} \mathrm{C}$, germination ranged from 36 to $59 \%$ after $24 \mathrm{~h}$ and from 13 to $47 \%$ after $48 \mathrm{~h}$. Other

TABLE 1. Relative humidity values over saturated solutions at various temperatures

\begin{tabular}{lccc}
\hline & \multicolumn{3}{c}{ Relative humidity $(\%)$} \\
\cline { 2 - 4 } Compound & $15^{\circ} \mathrm{C}$ & $20^{\circ} \mathrm{C}$ & $30^{\circ} \mathrm{C}$ \\
\hline $\mathrm{MgCl}_{2} \cdot 6 \mathrm{H}_{2} \mathrm{O}$ & 34.0 & 33.0 & 32.5 \\
$\mathrm{NaBr}_{2} 2 \mathrm{H}_{2} \mathrm{O}^{5}$ & 61.0 & 59.0 & 56.0 \\
$\mathrm{KNO}_{3}{ }^{11}$ & 95.5 & 93.5 & 91.0 \\
\hline
\end{tabular}




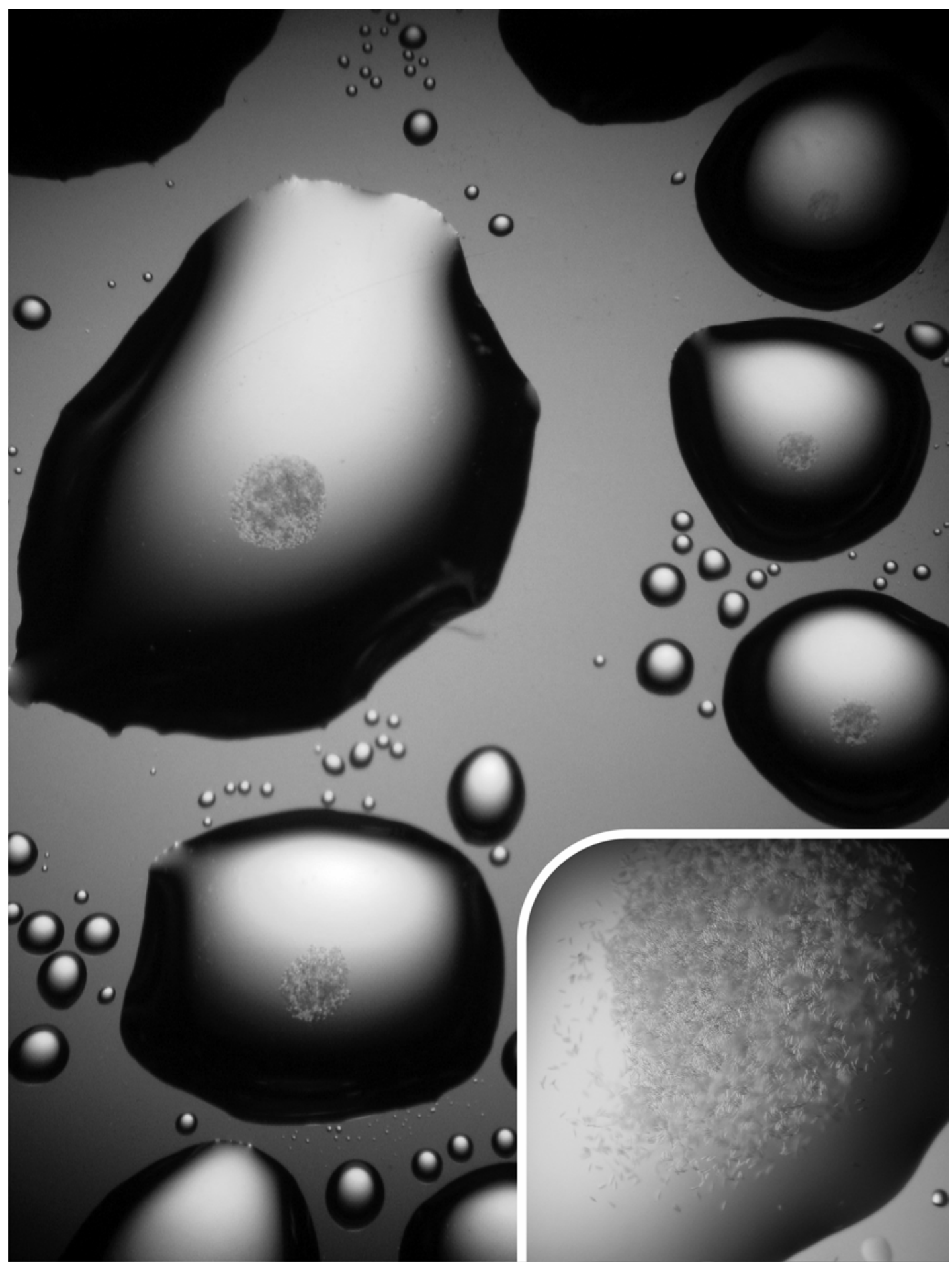

Fig. 1. Ascospores of Gibberella zeae trapped in condensation droplets suspended from petri dish lids.

TABLE 2. Tests of fixed effects of temperature (T) and relative humidity (RH), and contrasts from a linear model using a mixed procedure ${ }^{\mathrm{a}}$

\begin{tabular}{|c|c|c|c|c|c|c|c|c|}
\hline \multirow[b]{2}{*}{ Effect } & & \multicolumn{3}{|c|}{$4 \mathrm{~h}$} & \multicolumn{2}{|c|}{$24 \mathrm{~h}$} & \multicolumn{2}{|c|}{$48 \mathrm{~h}$} \\
\hline & & Num df & Den $\mathrm{df}$ & $F$ value & Den df & $F$ value & Den df & $F$ value \\
\hline $\mathrm{T}$ & & 2 & 23.1 & $4.08 *$ & 2.7 & $9.23+$ & 16.8 & $12.85^{* *}$ \\
\hline RH & & 2 & 19.1 & $36.9 * *$ & 6.7 & $9.05^{*}$ & 10.9 & 2.68 \\
\hline $\mathrm{T}$ Linear & & 1 & 23.8 & $7.20 *$ & 2.3 & $18.42 *$ & 16.6 & $25.71 * *$ \\
\hline $\mathrm{T}$ Linear & $30 \% \mathrm{RH}$ & 1 & 46.1 & $3.43+$ & 5.4 & $5.79+$ & 12.5 & $3.64+$ \\
\hline $\mathrm{T}$ Linear & $60 \% \mathrm{RH}$ & 1 & 43.2 & $16.3 * *$ & 5.7 & $19.80 * *$ & 12.5 & $20.20 * *$ \\
\hline
\end{tabular}

${ }^{a}$ Num df $=$ numerator degrees of freedom, Den $\mathrm{df}=$ denominator degrees of freedom; $*$ and $* *=$ significant at $P \leq 0.05$ and 0.01 , respectively; $+=$ significant at $0.05<P<0.10$ 
investigators have reported similar results showing that at any given $\mathrm{RH}$, increasing the temperature generally decreases the viability of fungal spores $(16,18)$.

The relationship between $\mathrm{RH}$ and spore survival is less clear. Germination was usually highest at $90 \% \mathrm{RH}$, lowest at $60 \% \mathrm{RH}$ and intermediate at $30 \% \mathrm{RH}$, with most pronounced loss of viability at $30^{\circ} \mathrm{C}$ (Fig. 2). Viable ascospores were found at all temperatures and RH levels tested, and all exposure periods. Teitell (18) reported that spores of different fungal species may retain or lose viability at different moisture levels. He found a narrow band of RH which has a lethal effect on conidia of certain strains of Aspergillus spp. The lethal RH shifted from $75 \%$ at $29^{\circ} \mathrm{C}$ to $81 \%$ at $45^{\circ} \mathrm{C}$.

In our study, ascospore discharge was observed 10 to 15 days after the filter paper colonized with $F$. graminearum was placed on carrot agar. This time course for development is comparable to that reported by Trail et al. (19), but not the $67 \pm 11$ days reported by Beyer and Verreet (2). Under natural conditions, ascospore discharge starts at approximately 1600 to $1700 \mathrm{~h}$ when $\mathrm{RH}$ is lowest, and peaks before midnight when $\mathrm{RH}$ is 65 to $85 \%(4,8$, 10). On the other hand under controlled conditions, Trail et al. (19) observed increased ascospore discharge with increasing RH. We may assume that discharge occurs when conditions are also appropriate for germination, i.e., when $\mathrm{RH}$ is high. Pritsch et al. (11) observed germ tube development and penetration occurring within 6 to $8 \mathrm{~h}$ following inoculation of wheat with macroconidia, while Beyer and Verreet (2) reported that the time to reach $50 \%$ ascospore germination ranged from more than $24 \mathrm{~h}$ to less than $4 \mathrm{~h}$ depending on conditions of $\mathrm{RH}$ and temperature. In nature, ascospores that are successfully deposited on host tissue during evening hours would have about $8 \mathrm{~h}$ of high $\mathrm{RH}(>85 \%)$ in which to germinate and start to penetrate the host.

Beyer and Verreet (2) observed no germination at RH less than $30 \%$ and concluded that germination would not occur below $50 \%$ $\mathrm{RH}$. However, they reported $8.2 \%$ germination at $52.6 \% \mathrm{RH}$, while at RH greater than $84 \%$, almost $100 \%$ germination occurred. They also noted that with increasing temperature, the rate of germination increased, requiring less than $4 \mathrm{~h}$ to reach $50 \%$ germination at 20 and $30^{\circ} \mathrm{C}$. At lower temperatures, the rate of germination was slower requiring more than $26 \mathrm{~h}$ at $4^{\circ} \mathrm{C}$ and 10.4 $\mathrm{h}$ at $14^{\circ} \mathrm{C}$. As we waited $24 \mathrm{~h}$ to count germinated ascospores we may assume that maximum germination had been reached for all temperatures and $\mathrm{RH}$ conditions tested. While Beyer and Verreet (2) reported $0 \%$ germination at $30 \% \mathrm{RH}$ they did get $8.2 \%$ at $53 \%$ RH. This compares with the lowest values we obtained at $60 \%$ $\mathrm{RH}$ and $30^{\circ} \mathrm{C}$ after $48 \mathrm{~h}$, but we obtained higher germination after exposure for $48 \mathrm{~h}$ to $\mathrm{RH}$ of $30 \%$ at all temperatures tested. These findings contradict those of Beyer and Verreet (2). However, there are reports that most fungal spores persist longer at low RH (18) and that temperature, not $\mathrm{RH}$, is the main climatic factor affecting longevity (17). Ayerst (1) reported that isolates of Aspergillus, Penicillium, and Stachybotrys were most tolerant of low water activity at temperatures close to the optimum and this may be true of $G$. zeae. In the present work, germination was generally highest at $15^{\circ} \mathrm{C}$ and decreased at 20 and $30^{\circ} \mathrm{C}$. As ascospore deposition is greatest at night $(15), 15^{\circ} \mathrm{C}$ may approximate the optimum temperature for germination under natural conditions.

Our results differed in some respects from those obtained by Beyer and Verreet (2). The failure in their study of ascospores to germinate after exposure to RH below $50 \%$ led them to conclude that long-distance transport of viable spores would be highly unlikely. In our study we recorded germination under all conditions tested, albeit low levels at $60 \% \mathrm{RH}$ and $30^{\circ} \mathrm{C}$. This may be the result of the different methods used in the experiments. To remove any variables that might provide moisture, we placed ascospores on inert glass surfaces for exposure to different temperatures and levels of RH, whereas in other studies ascospores were placed on water agar in the presence of silica gel,
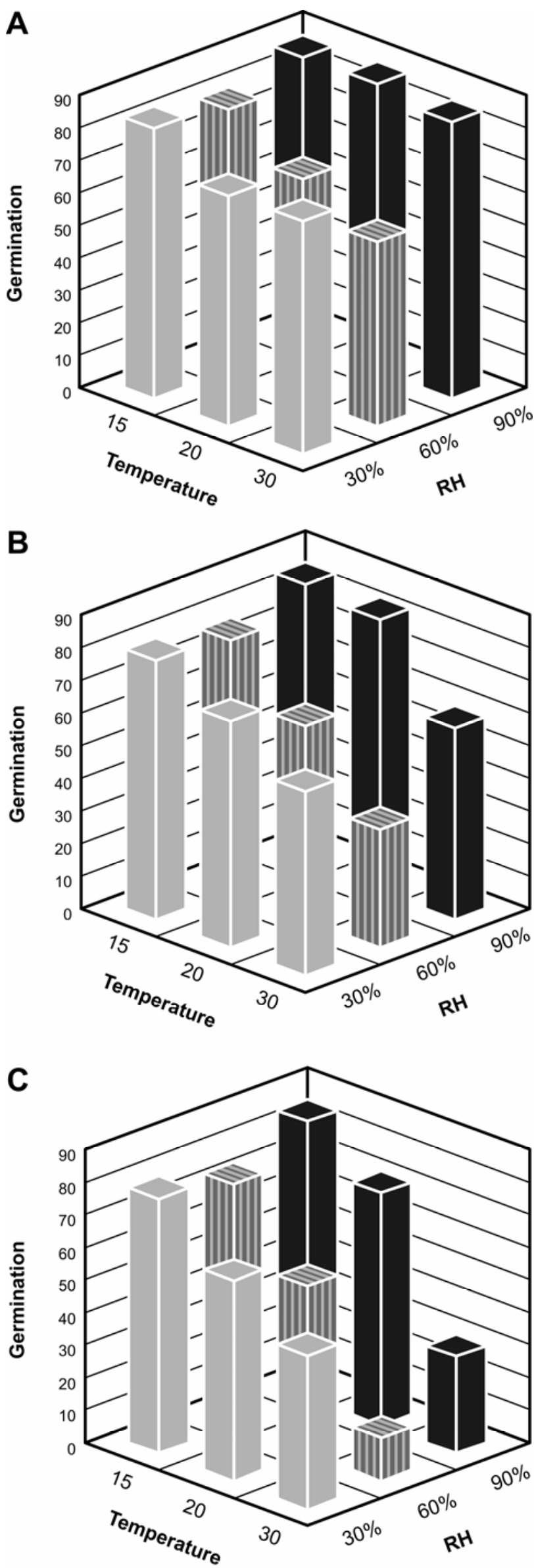

Fig. 2. Germination of Gibberella zeae ascospores after exposure to different temperatures and levels of relative humidity: A, 4 h; B, 24 h; and C, 48 h. 
water, or saturated salt solutions to vary RH $(2,17)$. To avoid any problems associated with immaturity, we took spores that were naturally discharged from perithecia as did Beyer and Verreet (2). Sung and Cook (17) on the other hand, crushed perithecia to obtain ascospores for their germination studies.

Ascospores retain their viability for a considerable length of time after discharge from the perithecium $(2,15)$. High levels of germination after $48 \mathrm{~h}$ at high $\mathrm{RH}$ were recorded in the present study. After deposition on both artificial (plastic) and natural wheat heads significant viability of macroconidia and ascospores was observed after 3 days exposure in natural environments (14), and Beyer and Verreet (2) indicated long-term viability up to 21.3 days following discharge. Ascospores are sufficiently robust to remain viable after release from perithecia under most environmental conditions experienced during the growing season on the Canadian prairies for extended periods of time. These results imply that cultural management of the disease at the local level will have limited effect in years where the weather favors development of FHB.

\section{ACKNOWLEDGMENTS}

We thank M. Shillinglaw for preparing the illustrations.

\section{LITERATURE CITED}

1. Ayerst, G. 1969. The effects of moisture and temperature on growth and spore germination of some fungi. J. Stored Prod. Res. 5:127-141.

2. Beyer, M., and Verreet, J.-A. 2005. Germination of Gibberella zeae ascospores as affected by age of spores after discharge and environmental factors. Eur. J. Plant Pathol. 111:381-389.

3. Dufault, N. S., De Wolf, E. D., Lipps, P. E., and Madden, L. V. 2006. Role of temperature and moisture in the production and maturation of Gibberella zeae perithecia. Plant Dis. 90:637-644.

4. Fernando, W. G. D., Miller, J. D., Seaman, W. L., Seifert, K., and Paulitz, T. C. 2000. Daily and seasonal dynamics of airborne spores of Fusarium graminearum and other Fusarium species sampled over wheat fields. Can. J. Bot. 78:497-505.

5. Fernando, W. G. D., Paulitz, T. C., Seaman, W. L., Dutilleul, P., and Miller, J. D. 1997. Head blight gradients caused by Gibberella zeae from area sources of inoculum in wheat field plots. Phytopathology 87:414-421.
6. Francl, L., Shaner, G., Bergstrom, G., Gilbert, J., Pedersen, W., DillMacky, R., Sweets, L., Corwin, B., Jin, Y., and Gallenberg, D. 1999. Daily inoculum levels of Gibberella zeae on wheat spikes. Plant Dis. 83:662666.

7. Gilbert, J., and Tekauz, A. 2000. Review: Recent developments in research of fusarium head blight in Canada. Can. J. Plant Pathol. 22:1-8.

8. Inch, S., Fernando, W. G. D., and Gilbert, J. 2005. Seasonal and daily variation in the airborne concentration of Gibberella zeae (Schw.) Petch. Can. J. Plant Pathol. 27:357-363.

9. Maldonado-Ramirez, S. L., Schmale, D. G., III, Shields, E. J., and Bergstrom, G. C. 2005. The relative abundance of viable spores of Gibberella zeae in the planetary boundary layer suggests the role of longdistance transport in regional epidemics of Fusarium head blight. Agric. For. Meteorol. 132:20-27.

10. Paulitz, T. C. 1996. Diurnal release of ascospores by Gibberella zeae in inoculated wheat plots. Plant Dis. 80:674-678.

11. Pritsch, C., Muehlbauer, G. J., Bushnell, W. R., Somers, D. A., and Vance, C. P. 2000. Fungal development and induction of defense genes during early infection of wheat spikes by Fusarium graminearum. Mol. PlantMicrobe Interact. 13:159-169.

12. SAS Institute, Inc. SAS OnlineDoc 9.1.3, Cary NC. 2004. http:support.sas.com/documentation/onlinedoc/913/docMainpage.jsp. Accessed March 11, 2008.

13. Schein, R. D. 1964. Comments on the moisture requirements for fungus germination. Phytopathology 54:1427.

14. Schmale, D. G., III, and Bergstrom, G. C. 2004. Airborne propagules of Gibberella zeae: Techniques for monitoring release and viability. (Abstr.) Phytopathology 94(suppl.):S93.

15. Schmale, D. G., III, Shields, E. J., and Bergstrom, G. C. 2006. Night time spore deposition of the Fusarium head blight pathogen, Gibberella zeae in rotational wheat fields. Can. J. Plant Pathol. 28:100-108.

16. Smilanick, J. L., and Mansour, M. F. 2007. Influence of temperature and humidity on survival of Penicillium digitatum and Geotrichum citriaurantii. Plant Dis. 91:990-996.

17. Sung, J.-M., and Cook, R. J. 1987. Effect of water potential on reproduction and spore germination by Fusarium roseum Graminearum, Culmorum, and Avenaceum. Phytopathology 71:499-504.

18. Teitell, L. 1958. Effects of relative humidity on viability of conidia of Aspergilli. Am. J. Bot. 45:748-753.

19. Trail, F., Xu, H., Loranger, R., and Gadoury, D. 2002. Physiological and environmental aspects of ascospore discharge in Gibberella zeae (anamorph Fusarium graminearum). Mycologia 94:181-189.

20. Winston, P. W., and Bates, D. H. 1960. Saturated solutions for the control of humidity in biological research. Ecology 41:232-237.

\section{Erratum}

Corrections were made to pages 504 and 508 of this article on July 11, 2008. Literature citations were incorrect. 